\title{
A Relationship Framework for Building Information Modeling (BIM) Capability in Quantity Surveying Practice and Project Performance
}

\author{
Un marco de relación entre la capacidad de BIM para la práctica de los \\ aparejadores y los resultados del proyecto
}

P. F. Wong ${ }^{(*)}$, H. Salleh ${ }^{(*)}$, F. A. M. Rahim ${ }^{(*)}$

\begin{abstract}
Construction industry has suffered from poor project performance and it's crucial to find out solution to improve this issue. Quantity surveyors (QSs) play a key role in managing project cost. However, their method of performing tasks is tedious till affect the project performance. Building information modeling (BIM) application is attaining attention in the construction industry as a mean to improve the project performance. However, the adoption is low among QSs due to limited study of the BIM's capabilities in their profession. This research aims to identify the BIM capabilities in quantity surveying practices and examine its relationship with project performance by developing a relationship framework. Data were collected through questionnaire survey and interview in Malaysia. Questionnaire results revealed that several BIM capabilities were significantly correlated with project performance and they were validated through interview. The relationship framework will guide QSs to focus on the identified BIM capabilities for better project outcomes.
\end{abstract}

Keywords: Building information modeling (BIM); quantity surveyors; capability; project performance; relationship framework.

\section{RESUMEN}

La industria de la construcción ha sufrido históricamente desviaciones en las mediciones de los materiales empleados frente a las cantidades proyectadas. Los aparejadores juegan un papel clave en este aspecto como responsables de la recepción de materiales. Sin embargo, el trabajo de medición es tedioso hasta el punto de afectar al rendimiento del proyecto. La aplicación del Building Information Modeling (BIM) está logrando mejorar este trabajo. Aun así, su utilización es baja entre los aparejadores debido a la escasa formación recibida sobre las posibilidades del BIM. Esta investigación busca identificar las capacidades del BIM aplicado a la medición de materiales y examinar su relación con el rendimiento del proyecto desarrollando un marco de relación. Mediante encuestas y entrevistas realizadas en Malasia, se obtuvieron datos que revelaron que varias capacidades de BIM se correlacionan de manera significativa con el rendimiento del proyecto. El marco de relación orientará a los aparejadores sobre las capacidades identificadas de BIM para obtener mejores resultados del proyecto.

Palabras clave: Building Information Modeling (BIM); aparejadores; capacidad; rendimiento del proyecto; marco de relación.

(*) University of Malaya. Lumpur (Malaysia).

Persona de contacto/Corresponding author: phuifung@gmail.com (P. F. Wong)

Cómo citar este artículo/Citation: Wong, P. F., Salleh, H., Rahim, F. A. M. (2015). A Relationship Framework for Building Information Modeling (BIM) Capability in Quantity Surveying Practice and Project Performance. Informes de la Construcción, 67(540): e119, doi: http://dx.doi.org/10.3989/ic.15.007.

Licencia / License: Salvo indicación contraria, todos los contenidos de la edición electrónica de Informes de la Construcción se distribuyen bajo una licencia de uso y distribución Creative Commons Reconocimiento no Comercial 3.o. España (cc-by-nc). 


\section{INTRODUCTION}

Completing a project on time and within budget as specified quality standards is a major criterion of success of a project in the construction industry (1). However, many construction projects have suffered from poor performance such as project delay and cost overrun (2) (3) (4). Al-Reshaid et al. (5) and Gibson and Hamiltion (6) explained that poor time and cost performance is due to bad planning of the project consultants during pre-construction stage. It is known that pre-construction stage is an influential stage and foundation for a successful project as many decisions on cost and time are made during this early stage which has an impact on the project performance. It's paramount to provide a series of accurate cost estimate at the early project stage for early decision as it has great influence on the project outcome (7). Hence, more efforts should devote at the early stage for better project performance.

Quantity surveyors (QSs) play an important role on providing cost management services in the construction industry. They are responsible for the cost management throughout the entire life span of a project from the feasibility and design stages until building completion. Among the services provided, building measurement is one of the major tasks provided by the QSs. However, this task is very time-consuming and is always prone to errors. Conventionally, the quantities are calculated by hand from paper drawings or using quantity surveying software based on 2D drawings and then, the dimensions are transferred on excel spreadsheet to perform estimation. The time spent by the QSs varies by project, but around $50-80 \%$ of the time needed to create a cost estimate is spent on quantification (8). Mitchell (7) also commented that QSs spend $90 \%$ of their time on calculating building quantities. However, these tedious and time consuming tasks performed by QSs can be eradicated by automating the process by implementing building information modeling (BIM). BIM technology is a potential solution for the above problems by automating the tedious tasks (9) which allow the QSs to devote their time to other value-added services.

BIM is defined as an associated set of modeling processes to produce, insert, share and manage the information in a centralized model to improve the designs, construction, operations and maintenance processes. It is a replacement to conventional working methods and can assist QSs in the generation of accurate quantity take offs and cost estimates throughout the project lifecycle. BIM eliminates many tedious tasks of traditional quantity surveying, such as measurement, take offs, and production of bills of quantity (BQ). BIM has the potential to revolutionize the quantity surveying practice by taking away the tediousness of the tasks and thus enhance the job performances of QSs. However, compared to architects and engineers, QSs lagged behind in BIM application (10). According to Royal Institute of Chartered Surveyors (RICS) survey conducted in 2011, $10 \%$ of QSs were using BIM regularly and further $29 \%$ of QSs have some limited engagement with BIM (11). This survey revealed that low BIM usage among QSs is due to lack of awareness and being unsure of its potential usability in their practice.

There are limited of studies on the potential of BIM in cost management activities such as cost planning, estimation and quantification (4) which results in low awareness among QSs. It was found that one of the factors caused low awareness is lack of information regarding BIM application along with the uncertain capability of new technology has caused the QSs reluctance to implement BIM. This situation has made them default back to conventional working methods which impede their job performance. In order to improve this situation, it is crucial to create greater awareness of the potential and benefits of BIM in surveying practice (11) (12). Prior studies have addressed the importance of adopting BIM in the construction industry (4) (7) but not focusing on the quantity surveying profession. Therefore, this paper aims to identify the capabilities of BIM in quantity surveying practice. This is followed by examining the relationship between BIM capabilities and project time and cost performances; then, to develop a regression model for prediction purpose on project performance. Lastly, a relationship framework is developed to show the relationship between BIM capabilities in quantity surveying practice and project performance.

This study potentially provides three key contributions to the extant literature. First, it is expected to raise research interest on BIM application in quantity surveying practice. It adds to literature on the list of BIM capabilities in quantity surveying practice. The importance of recognizing and understanding how BIM application may contribute to performance of QSs is highlighted. It will gain QSs' understanding of the potential and ability of BIM process in their practice; leading to job performance improvement as compared to traditional inefficient practice. Second, this study contributes to the body of literature by examining the relationship between BIM capabilities in quantity surveying practice and project performance. Specific analyses on the relationship of BIM capabilities and project performance are relatively limited. Therefore, the study results can provide an insight to QSs on how to achieve better project performance in terms of time and cost by using BIM. Third, the relationship framework developed can be used as a guide and inform the QSs practice on which of the relationships shall be governed.

\section{LITERATURE REVIEW}

Many of the previous studies conducted to study the BIM application in cost management aspect or quantity surveying practice. Olatunji et al. (4) explored the relationship between the roles of QSs and BIM in the construction industry. They highlighted that BIM has the potential to revolutionize the quantity surveying practice. Smith (13) discussed the opportunities and challenges of cost professions of embracing $5 \mathrm{D}$ $\mathrm{BIM}$ applications in order to become $5 \mathrm{D}$ project cost manager in the BIM environment. Thurairajah and Goucher (14) focused on the usability and impact of BIM for cost consultants. Their finding indicated that time saving is one of the key advantages of BIM for cost consultants during the cost estimating stage. Matipa et al. (15) explored the impact of the new rules of measurement on the building information model schema pertinent to the QSs. Besides, several authors conducted a study to examine the current BIM application in quantity surveying practice in their country respectively. Stanley and Thurnell (16) presented the benefits and barriers of 5 D BIM application by QSs in Auckland through interviews. In Sri Lanka, Nagalingam et al. (9) explore the potential expansion of the role and responsibilities of QSs in a BIM based project delivery.

In term of BIM application in cost estimating process, few authors have made an effort on it. Cheung et al. (17) detailed 
the cost estimation module that enables quick and intuitive exploration of early stage design in a $3 \mathrm{D}$ environment; by proposing an intuitive method of incorporating cost (and multi-level) estimation into the early stage of design. Monteiro and Pocas Martins (18) presented a case study to survey BIM input/output dynamics for quantity take off, examine model behavior when constrained by existing specifications for quantity take off and also detailing modeling guidelines. In view of the importance for monitor construction project, Elbeltagi et al. (19) developed a model and framework to project participants that integrates BIM visualization, project cost estimates and cost monitoring/control techniques. Lee et al. (20) proposed an ontological approach for cost estimators to automate the process of searching for the most appropriate work items. Staub-French et al. (21) developed an IFCbased cost estimating system that can directly use the results of IFC files and automatically apply corresponding prices for cost estimation. Further, many of the studies focused on the BIM application in life cycle costing. Examples of those studies include Ma et al. (22) and Nour et al. (23).

These and other earlier studies have discussed the BIM utilization for QSs, concept of BIM in cost management aspects, BIM application in cost estimating stage and life cycle cost. Moreover, few studies developed standard, model and framework for BIM application in cost estimating process. However, there were very limited studies on the capabilities of $5 \mathrm{D}$ BIM or BIM capabilities in quantity surveying practice. As addressed by Wang et al. (24), the study of how BIM can help QSs in a project is rare. The relationship between BIM capabilities in quantity surveying practice and project performance has not been investigated. Generally, many scholars have identified that BIM implementation can reduce project time and cost. However, little attempts have been made to explore the capabilities of BIM in quantity surveying practice during pre-construction stage. Additionally, few studies have been made to explore the relations between BIM capabilities in quantity surveying practice during pre-construction stage and project performance. Hence, this study is intended to fill this gap by studying the relationship of BIM capabilities in quantity surveying practice during pre-construction stage associated with project performance in time and cost aspect.

\section{RESEARCH METHODOLOGY AND ANALYSIS}

The choice of research methodology is depends on the nature of the research subject, aims and the research questions (25) (26). In this instance, the nature of the research and aim is to examine the relationship between BIM capabilities in quantity surveying practice (independent variables) and project performance (dependent variables). It was found that a mixed method of quantitative and qualitative approach is suitable for this study. Quantitative results provide the significant relationship between BIM capabilities and project performance, whereas qualitative results help to explain why certain capabilities identified are significant to the project performance to provide a better understanding of the relationship. In construction research, previous studies conducted by several authors (3) (27) also adopted mixed method of quantitative and qualitative for the purpose of exploring the relationships between the independent and dependent variables.

Creswell (28) pointed out that there are three types of mixed method designs: triangulation, explanatory and exploratory.
The purpose of triangulation design is to simultaneously collect both quantitative and qualitative data for comparing and contrasting the both results to determine if the two results yield similar or dissimilar results. Explanatory design is suitable when the researcher requires qualitative data to refine the results from the quantitative data. Exploratory design is popular for exploring a phenomenon, identify variables, design an instrument during qualitative approach and then subsequently test the instrument during quantitative approach. By comparing these three mixed methods designs, it was found that explanatory is appropriate for this study to achieve the aim of the study. Explanatory mixed methods design is a sequentially two distinct data collection procedures whereby the researcher collects quantitative data first and then collects qualitative data to help explain or elaborate further on the quantitative results. The rational for choosing this research design is quantitative data and results provide a general picture of the research problem while qualitative data serve as a follow-up purpose to help to refine or further elaborate the quantitative findings in more depth.

In order to identify BIM capabilities and examine the relationship between BIM capabilities with project performance, this study was designed into four phases. The study began with a detail literature review to identify the BIM capabilities in quantity surveying practice during pre-construction stage. After reviewing the literatures, there were eleven BIM capabilities in quantity surveying practice that have been identified. The eleven BIM capabilities obtained along with their identification numbers $(\mathrm{C} 1, \mathrm{C} 2, \mathrm{C} 3 \ldots, \mathrm{C} 11)$ were displayed in Table 1 . Phase 2 of the study involved preliminary interview to serve as a purpose of pilot study to verify the BIM capabilities that identified through literature review. It is important to confirm the identified capabilities are reflected to the current quantity surveying practice. The selected interviewees were chosen to have at least 10 years of experience in the construction industry and had used BIM in their practice. The interview results reached saturation after eight interviews. The preliminary interview concluded that the identified eleven BIM capabilities through literature review were confirmed by the interviewees.

At phase 3, main data collection was begun with questionnaire distribution to quantity surveying firms in Malaysia. Quantity surveying firms that have adopted BIM in practice were the main target respondents. Pilot study was undertaken to pre-test the survey and subsequently modified before the industry-wide survey. Altogether, 325 questionnaires were delivered and each respondent was given 2-3 weeks to return the questionnaires. Finally, 103 valid questionnaires were received representing a $32 \%$ response rate. The responses received were analyzed through Statistical Package for Social Science (SPSS) software.

Spearman's rho correlation test was used to determine the relationship between BIM capabilities and project performance. There is a significant relationship if the probability is less than 0.05. Subsequently, this study adopted binary logistic regression to investigate the effect of BIM capabilities on project performance. By adopting this method, which of the BIM capabilities affect the project performance can be known from the result. Prediction model for project performance can be produced to understand further the relationship between capabilities and project performance. Binary logistic regression was selected for this study because the dependent varia- 
Table 1. BIM capabilities in quantity surveying practice.

\begin{tabular}{|l|l|}
\hline Tag & \multicolumn{1}{|c|}{ Capability } \\
\hline C1 & $\begin{array}{l}\text { Cost appraisal can be prepared quickly at the feasibility stage } \\
(7,59)\end{array}$ \\
\hline C2 & $\begin{array}{l}\text { Preliminary cost plan can be prepared by extracting quantities directly from the model } \\
(7,9,21)\end{array}$ \\
\hline C3 & $\begin{array}{l}\text { Easily update cost plans with more detail as design is developed } \\
(7,9,10,21,60)\end{array}$ \\
\hline C4 & $\begin{array}{l}\text { Easily generate accurate cost estimates for various design alternatives } \\
(7,9,21,61,62)\end{array}$ \\
\hline C5 & $\begin{array}{l}\text { Design changes reflected consistently in all drawing views } \\
(60,62,63)\end{array}$ \\
\hline C6 & $\begin{array}{l}\text { Cost implication of design changes can be generated easily without manually re-measurement } \\
(10,27,52,61,62)\end{array}$ \\
\hline C7 & $\begin{array}{l}\text { Clash detection reduces design errors and cost estimate revisions } \\
(10,64,65)\end{array}$ \\
\hline C8 & $\begin{array}{l}\text { Cost checking performs quickly to ensure all items are capture } \\
(60,62)\end{array}$ \\
\hline C9 & $\begin{array}{l}\text { Improved visualization for better understanding of designs } \\
(10,19,66,67,68)\end{array}$ \\
\hline C10 & $\begin{array}{l}\text { Automatically quantification for BQ preparation } \\
(9,22,61,68)\end{array}$ \\
\hline C11 & $\begin{array}{l}\text { Intelligent information management system allows data to be stored in a central coordinated model } \\
(10,21,61,68)\end{array}$ \\
\hline
\end{tabular}

bles were ordinal on a scale. Besides, the application of logistic regression requires no assumptions such as multivariate normality, linearly related or of equal variance which making its application appropriate in many situations (29). The objective of using logistic regression is to predict the probability that an event will occur. In this study, the probability of project performance in term of time and cost can be predicted (good or poor) based on the 11 BIM capabilities in quantity surveying practice listed in Table 1 . The project performance has been rated by respondents on the outcome of a BIM project from a 5-point scale. The 5-point scale was re-coded into dichotomous variables (good and poor performances). The analysis was based on the "forward logistic method" by using SPSS. The relationship can be expressed in the form of:

$$
\operatorname{Logit}(Y)=\operatorname{In}\left[\frac{\pi}{1-\pi}\right]=\alpha+\beta_{1} X_{1}+\beta_{2} X_{2}
$$

Where,

$Y=$ dependent variables

$\pi=$ probability of the event

$\alpha=$ Intercept

$\beta_{1}, \beta_{2}=$ regression coefficients

$X_{1}, X_{2}=$ independent variables

The last stage of the study was validation of questionnaire results by conducting semi-structured interviews. Interview is a suitable method to serve as a follow up purpose to validate the questionnaire's results by examining interviewees' opinions. The interview results reached saturation after fifteen interviews with QSs. All selected respondents have more than 5 years of experience in the construction industry and had used BIM for construction projects. Most of the interview discussions centered on the capabilities of BIM in quantity surveying practice and in relation to project performance. Interviews were recorded, transcribed, and analyzed using content analysis. Content analysis is a process served to reduce massive volumes of data by coding to examine themes and patterns in a particular text in order to explore the meaning based on interpretation. At the end of the con- tent analysis, the results are consolidated in a relationship framework.

\section{RESEARCH FINDINGS AND DISCUSSIONS}

\subsection{Relationship between BIM capabilities and project performance}

The relationship between BIM capabilities and project performance in time and cost was identified and tabulated in Table 2. In time aspect, nine BIM capabilities were identified correlated significantly which are $\mathrm{C}_{1}, \mathrm{C}_{2}, \mathrm{C}_{3}, \mathrm{C} 4, \mathrm{C} 7, \mathrm{C} 8, \mathrm{C} 9$, C10 and C11 with correlation coefficient of .252, .400, .284, $.394, .275, .296, .342, .275$ and .275 respectively. Among the eleven capabilities, eight capabilities are $\mathrm{C}_{2}, \mathrm{C}_{3}, \mathrm{C}_{4}, \mathrm{C}_{5}, \mathrm{C} 6$, $\mathrm{C}_{7}, \mathrm{C} 9$ and $\mathrm{C} 10$ were found to be significantly correlated to project cost performance with correlation coefficient of .236, $.192, .294, .249, .283, .240, .272$ and .288 respectively.

Findings revealed that $\mathrm{C} 1$ is correlated with the project time performance. BIM has the capability in strengthening the quality of decision made at this early stage based on quick feedback on the feasibility to avoid time wasted. Realizing that a project is over budget and not feasible at the beginning stage can ensure the time performance which allows the project team to seek for better other feasible alternatives. By getting cost appraisal early from the QSs, interviewees asserted that this contributed to timely feedback on the design and allow for early modification, which avoid the potential delay associated with later stage changes. As a result, this capability has an impact on time performance.

The findings indicated that $\mathrm{C} 2$ is correlated with time and cost performance. Preliminary cost plan can be prepared faster and accurately by using BIM. Quantity can be extracted directly from the model. Hence, it reduces human error and subsequently enhances project time and cost performance. The statement by Nagalingam et al. (9) pointed out that project time is saved and cost overrun can be avoided as 
Table 2. Correlation between capabilities of BIM and project performance in time and cost aspect.

\begin{tabular}{|c|c|c|}
\hline \multirow{2}{*}{ Tag } & \multicolumn{2}{|c|}{ Correlation Coefficient } \\
\hline & Time & Cost \\
\hline $\mathrm{C} 1$ & $.252^{* *}$ & .173 \\
\hline $\mathrm{C} 2$ & $.400^{* *}$ & $.236^{*}$ \\
\hline $\mathrm{C}_{3}$ & $.284^{* *}$ & $.192^{*}$ \\
\hline $\mathrm{C}_{4}$ & $.394^{* *}$ & $.294^{* *}$ \\
\hline $\mathrm{C}_{5}$ & .101 & $.249^{* *}$ \\
\hline C6 & .187 & $.283^{* *}$ \\
\hline $\mathrm{C}_{7}$ & $.275^{* *}$ & $.240^{*}$ \\
\hline $\mathrm{C} 8$ & $.296^{* *}$ & .138 \\
\hline C9 & $.342^{* *}$ & $.272^{* *}$ \\
\hline C10 & $.275^{* *}$ & $.288^{*}$ \\
\hline C11 & $.275^{* *}$ & .176 \\
\hline
\end{tabular}

preliminary cost estimate can be prepared quickly is hence supported. The interviewees also pointed out that QSs would extract the information contained in the model accurately in a shorter time. By getting cost plan earlier and accurately by the QSs, project client can have a conceptual idea of the project scope. Any misinterpretation in the cost plan can be realized and solved earlier before it impacts to the project. This in turn eliminates construction issues at the early stage and reduces change orders during later stage which can ensure the project performance.

The $\mathrm{C}_{3}$ is correlated with time and cost performance as shown in the results. Manual practice is prone to errors as the QSs need to detect many changes and updates in quantities and costing. BIM has the capability to allow them to update the cost plan automatically. This aligns with Gee (30) who asserted that BIM allows rapid updating quantities in the cost plan, so that design develops within project scope and avoid unnecessary expenses. Interviewees pointed out that frequent and easy updates cost plan by using BIM allow early notification to the project team if the design is out of budget and schedule at the earlier stage. This ensure project performance which avoid any major variation that can affect project time and cost.

$\mathrm{C}_{4}$ is identified as correlated with the time and cost performance. BIM allows QSs to generate various cost estimates for different design alternatives. Quantities can be quickly and easily changed to see how the project will be affected with respect to cost and time in different design options. The statement by Gee (30) revealed that client will be able to consider for different design alternatives by evaluating the costs related to the alternatives which can result in valuable cost savings and resources utilization. Majority of the interviewees mentioned that this capability enables the QSs to explore various design alternatives and what-if scenarios to optimize the building performance before construction. In turn, it enhances the project performance as the client can choose few alternatives to evaluate different designs or material options to determine which are the most beneficial. Subsequently it eliminates costly and timely traditional construction design or methods.

The analysis findings also displayed that $\mathrm{C}_{5}$ is correlated with the cost performance. If a design on a drawing is changed, then all other drawings of this part also need to be revised. Manual revision is time consuming as many drawings view affected by the changes made. If changes do not updated in all drawing views, QSs have a tendency to miss out some elements which affect the project cost. However, Burns and McDonnell (31) stated that BIM allows a greater flexibility for revisions during the time when design changes which have the positive impact on construction cost. Interviewees explained that changes made in any representation are propagated to all views and thus, all the representations were coordinated. With this capability, it ensures accuracy for the latest iteration of the design and avoids QSs from using obsolete drawings for cost estimating that may affect the cost performance.

The C6 revealed as correlated with the cost performance. QSs struggled with the ability to respond to the design and requirement changes and to understand the impact of those changes on the overall project budget. This is because remeasurement is tedious and mistakes tend to occur that make costing inaccurate. This capability will generate cost implication automatically when the design changes. Hence, the cost performance is enhanced with less human error. The findings verified that Gee (30) who mentioned that the project cost can be managed efficiently as cost implications regarding the changes were shown at early project stages. Interviewees stated that cost implication was a concern for the client as it influences the project budget. Hence, it is important for QSs to generate cost implications to show the cost differences which allow the clients to see how the changes affect the total cost of a building.

$\mathrm{C}_{7}$ is found to be correlated with the project cost and time performance. This is supported by Ghanem and Wilson (32) who demonstrated BIM application through a case study on a project by showing BIM application is able to reduce cost by detecting clashes at early stage. Interviewees explained that design deficiencies would cause change order which incur extra costs and project delays. With this capability, design errors can be detected earlier and resolved earlier before it brings negative impact on project performance. According to most interviewees, they are able to identify design clashes by using BIM which help to rectify the design errors before the construction begins.

C8 is displayed correlated with the project time performance. This is consistent with Jiang (33) who ascertained errors and omissions can be significantly reduced at the early stage and thus speeding up the construction process or shortening the construction period. QSs can quickly check for excessive or missing quantities in the model to confirm the accuracy and completeness of the quantification. Interviewees explained that visual checking on BIM model allows QSs to perform checking easily and it reduces the possibility of omissions. By doing this, it avoids project delays that caused by omissions due to oversight by the QSs.

Analysis results displayed that $\mathrm{C} 9$ is correlated with the project time and cost performance. Shen and Issa (34) conducted a test and proved that the $3 \mathrm{D}$ visualization can show the performance improvement in terms of time and cost. The statement is proven by the analysis result. Interviewees agreed that by enhancing the QSs' understanding on design using this capability; they are able to interpret design accurately and captured a precise costing. It allows QSs to grasp the details quickly and easily without confusion. Subsequently 
it reduces misinterpretation, making wrong assumption and minimizes risk of making mistakes during early stage. Hence, it ensures project performance.

The findings demonstrated that $\mathrm{C} 10$ is correlated with time and cost performance. QSs have the tendency to capture inaccurate costing which affect the project cost performance and project delays. Mistakes could occur such as double counting and missed out elements as the project consists of multiple elements and drawings. However, through automatically calculated quantity take offs which extracted directly from the model, cost savings can be achieved as mentioned by Hsu (35). One of the interviewees shared the experience of adopting BIM in practice; the project achieved cost savings as quantity take off was completed accurately which allow the construction team to purchase exact materials needed and thereby reduce wastage. Thus, it ensures the cost performance.

Findings indicated that $\mathrm{C} 11$ is correlated with the time performance. Information sharing in paper-based often cause miscommunication and information breakdown that have serious impact on project time performance. Part of the QSs' tasks involves collating and clarifying information from different design consultants which will lead to non-productive and inefficient work that affect time performance (36). BIM acts a central database with all information stored and accessible by all project parties. The statement of Aibinu and Venkatesh (36) highlighted BIM provides a platform for integrated information exchange through a single model which will enhance time performance. The quick and easy access to information helps the QSs in expediting their work performance. According to majority of the interviewees, by having timely and promptly information and documents, QSs can perform their tasks efficiently by providing advice to clients which lead to improvement in client decision making that could impact on project time performance.

\subsection{Developing the regression model}

Logistic regression analysis was performed by using the eleven BIM capabilities as the predictors. In the analysis, project performance was coded into dichotomous variables which are good -1 - and poor $-0-$ performance. The analysis begins with the selection of statistically significant BIM capabilities (independent variables) to be included through a stepwise method.

\subsubsection{Time performance}

As shown in Table 3, SPSS produced four steps to include the predictor that significantly contributed to the logistic regression model. During the Step 1 selection process, C2 with highest chi-square score (15.496) that meets the p-value criterion (significant at 0.05) is selected in the model. Step 2 revealed C8 significantly predicting the time performance with chi-square score of 6.117 ( $\mathrm{p}<.05)$. Step 3 included C9 with chi-square score of 5.937. At Step 4, C2 removed from the model reduce the chi-square value of 0.635 . The whole process stopped and the final model consists of two independent variables. Hence, the two independent variables of $\mathrm{C} 8$ and $\mathrm{C} 9$ are significantly predicting the time performance (total chisquare value $=26.915, \mathrm{p}<.05$ )

Meanwhile, the p-value for Hosmer and Lemeshow goodness of fit is .906, which is more than .05. Thus, the model adequately fit the data. As can be seen, $48.4 \%$ of the variance in time performance could be predicted from the capability C8 and C9. Both variable coefficients are statistically significant at the $5 \%$ level. This indicates that the model is good in prediction of project time performance. The result demonstrates that these two variables have an effect on the time performance. The logistic regression equation is produced as follows (see Table 3).

$$
Z=-9.663+2.210(C 8)+2.015(C 9)
$$

Thus, C8 and C9 are the two variables that influence the project time performance. If QSs focuses on these two BIM capabilities, the project time performance would most likely to be improved. Understanding of this relationship could help QSs targeted on these two BIM capabilities. It is then QSs should adopt BIM in their practice not only to improve their performance but also project time performance.

\subsubsection{Cost performance}

As shown in Table 4, SPSS produced two steps to include the predictor that significantly contributed to the logistic regression model. During the Step 1 selection process, C10 with highest chi-square score (8.922) that meets the p-value criterion (significant at 0.05) is selected in the model. Step 2 revealed $\mathrm{C}_{4}$ significantly predicting the cost performance with chi-square score of $4.790(p<.05)$. The whole process stopped and the final model consists of two independent vari-

Table 3. Logistic regression result for time performance.

\begin{tabular}{|c|c|c|c|c|c|c|c|c|c|}
\hline \multirow{2}{*}{\multicolumn{2}{|c|}{ Predictor }} & \multirow{3}{*}{$\begin{array}{c}\text { B } \\
1.698 \\
\end{array}$} & \multirow{3}{*}{$\begin{array}{l}\text { S.E. } \\
.500 \\
\end{array}$} & \multirow{3}{*}{\begin{tabular}{|l} 
Wald \\
11.535 \\
\end{tabular}} & \multirow{3}{*}{$\begin{array}{l}\text { Sig. } \\
.001 \\
\end{array}$} & \multicolumn{2}{|c|}{ Model fit information } & \multicolumn{2}{|c|}{ Pseudo R-square } \\
\hline & & & & & & Chi-Square & Sig. & Cox \& Snell & Nagelkerke \\
\hline \multirow{2}{*}{ Step $1^{\mathrm{a}}$} & Cap 2 & & & & & \multirow{2}{*}{15.496} & \multirow{2}{*}{.003} & \multirow[b]{2}{*}{.137} & \multirow{2}{*}{.294} \\
\hline & Constant & -2.428 & 1.274 & 3.632 & .057 & & & & \\
\hline \multirow{3}{*}{ Step $2^{b}$} & Cap 2 & 1.557 & .511 & 9.299 & .002 & \multirow{3}{*}{6.117} & \multirow{3}{*}{.029} & \multirow{3}{*}{.186} & \multirow{3}{*}{.398} \\
\hline & Cap 8 & 1.401 & .614 & 5.211 & .022 & & & & \\
\hline & Constant & -6.423 & 2.293 & 7.846 & .005 & & & & \\
\hline \multirow{4}{*}{ Step $3^{\mathrm{c}}$} & Cap 2 & .592 & .736 & .648 & .421 & \multirow{4}{*}{$5 \cdot 937$} & \multirow{4}{*}{.015} & \multirow{4}{*}{.231} & \multirow{4}{*}{.494} \\
\hline & Cap 8 & 2.058 & .785 & 6.870 & .009 & & & & \\
\hline & Cap 9 & 1.600 & .764 & 4.387 & .036 & & & & \\
\hline & Constant & -9.821 & 3.269 & 9.026 & .003 & & & & \\
\hline \multirow{3}{*}{ Step $4^{\mathrm{c}}$} & Cap 8 & 2.210 & .769 & 8.256 & .004 & \multirow{3}{*}{-.635} & \multirow{3}{*}{.010} & \multirow{3}{*}{.226} & \multirow{3}{*}{.484} \\
\hline & Cap 9 & 2.015 & .623 & 10.461 & .001 & & & & \\
\hline & Constant & -9.663 & 3.211 & 9.055 & .003 & & & & \\
\hline
\end{tabular}


Table 4. Logistic regression result for cost performance.

\begin{tabular}{|c|c|c|c|c|c|c|c|c|c|}
\hline \multirow{2}{*}{\multicolumn{2}{|c|}{ Predictor }} & \multirow{3}{*}{$\begin{array}{c}\text { B } \\
1.741 \\
\end{array}$} & \multirow{3}{*}{$\begin{array}{l}\text { S.E. } \\
.660 \\
\end{array}$} & \multirow{3}{*}{$\begin{array}{l}\text { Wald } \\
6.970 \\
\end{array}$} & \multirow{3}{*}{$\begin{array}{l}\text { Sig. } \\
.008 \\
\end{array}$} & \multicolumn{2}{|c|}{ Model fit information } & \multicolumn{2}{|c|}{ Pseudo R-square } \\
\hline & & & & & & Chi-Square & Sig. & Cox \& Snell & Nagelkerke \\
\hline \multirow{2}{*}{ Step $1^{a}$} & Cap10 & & & & & \multirow{2}{*}{8.922} & \multirow{2}{*}{.003} & \multirow{2}{*}{.081} & \multirow{2}{*}{.210} \\
\hline & Constant & -3.797 & 2.273 & 2.791 & .095 & & & & \\
\hline \multirow{3}{*}{ Step $\mathbf{2}^{\mathbf{b}}$} & Cap4 & 1.133 & .568 & 3.974 & .046 & \multirow{3}{*}{4.790} & \multirow{3}{*}{.029} & \multirow{3}{*}{.122} & \multirow{3}{*}{.316} \\
\hline & Cap10 & 2.002 & .802 & 6.226 & .013 & & & & \\
\hline & Constant & -8.150 & 3.496 & 5.435 & .020 & & & & \\
\hline
\end{tabular}

ables. Hence, the two independent variables of $\mathrm{C}_{4}$ and $\mathrm{C} 10$ are significantly predicting the cost performance (total chisquare value $=13.712, \mathrm{p}<.05$ )

Meanwhile, the p-value for Hosmer and Lemeshow goodness of fit is .903, which is more than .05. Thus, the model adequately fit the data. As can be seen, $31.6 \%$ of the variance in cost performance could be predicted from the capability $\mathrm{C} 1 \mathrm{O}$ and $\mathrm{C}_{4}$. Both variable coefficients are statistically significant at the $5 \%$ level. This indicates that the model is good in prediction of project cost performance. The result demonstrates that these two variables have an effect on the cost performance. The logistic regression equation is produced as follows (see Table 4).

$$
Z=-8.150+1.133\left(\mathrm{C}_{4}\right)+2.002(\mathrm{C} 10)
$$

Thus, $\mathrm{C}_{4}$ and $\mathrm{C} 10$ are the two variables influence the project cost performance. If QSs focuses on these two BIM capabilities, the project cost performance would most likely to be improved. Understanding of this relationship could help QSs targeted on these two BIM capabilities. It is then QSs should adopt BIM in their practice not only to improve their performance but also project cost performance.

\subsection{Relationship Framework of BIM Capabilities and Project Performance}

The interview results validated the questionnaire survey results by ascertaining QSs' views concerning the BIM capabilities and their relationship with project performance. The experiences of interviewees by using the identified BIM capability for construction project have been reported to provide more concrete information on the relationship identified between BIM capability and project performance. The results from the interviews highlighted that there is a relationship between BIM capabilities in quantity surveying practice during pre-construction stage and project performance in time and cost aspect. Hence, the identified BIM capabilities have an impact on project performance.

In this study, it was found out that project performance in the aspect of time and cost were improved when QSs adopted BIM capabilities in their practice during pre-construction stage. These results lend support to the suggestion that by adopting BIM in quantity surveying practice during preconstruction stage, QSs can perform efficiently; the project performance is more likely to enhance. Hence, BIM adoption in quantity surveying practice during pre-construction stage is key practice necessary to improve project performance. It is due to more effort spend during pre-construction stage is critical to improve project time and cost performance (6) than efforts undertaken after the project is started. Many crucial decisions are made during this early stage as the impact

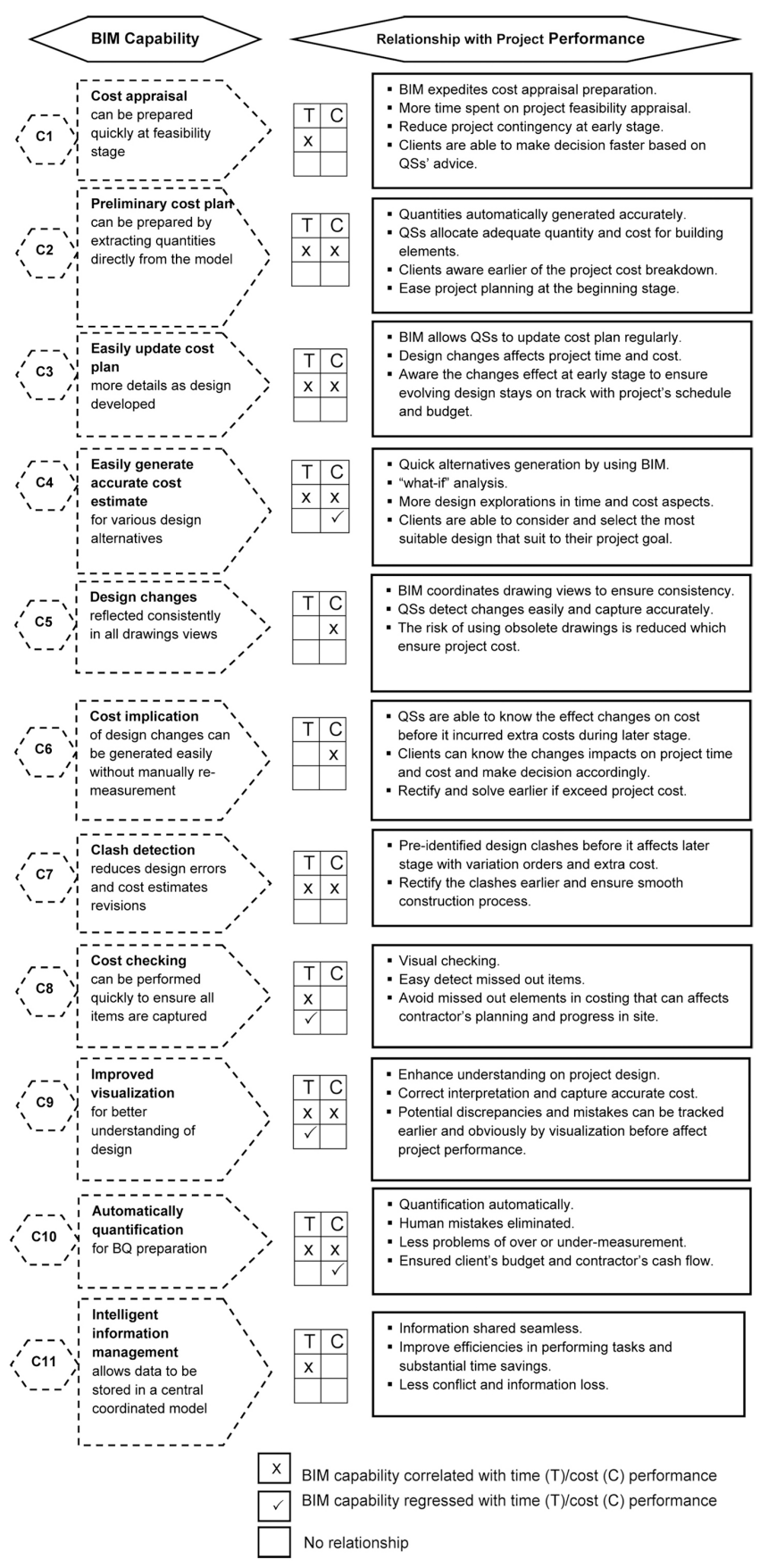

Figure 1. Relationship framework of BIM capabilities in quantity surveying practice and project performance.

of these decisions made early is usually greater than later stages.

When QSs adopt BIM for practice, many decisions can be made at the early stage based on their professional advice, 
which ultimately have significant impact on the project outcome. Thus, it is essential to adopt BIM by QSs during this early stage. QSs are able to gain efficiency in performing their works by using BIM during early stage which will affect the project performance. This leads to a more efficient project outcome that stays on budget and schedule. It aligns with Aibinu and Venkatesh (36) who asserted that BIM enhances the accuracy in quantity take off which would impact on cost estimating and also other services provided by the QSs which in turn have positive implications for a project as a whole.

Lastly, a relationship framework has been established to present the relationship between BIM capabilities in quantity surveying practice during pre-construction stage and project performance in time and cost aspect as depicted in Figure 1. By organizing the identified relationships into a framework, it could make the BIM capabilities and relationship more accessible and obvious to the QSs for reference and increase understanding. QSs should focus on these identified BIM capabilities to further streamline their roles. It creates better overall project outcomes for the project.

\section{CONCLUSION}

Although the evolution of BIM will undoubtedly plays an important catalyst role in the future, many QSs are still unsure of the capabilities of BIM. BIM application in quantity surveying practice has received less attention as most of the studies focused on BIM application in terms of design perspectives. Several studies have addressed the importance of adopting BIM in the construction industry. However, specific capabilities of BIM in quantity surveying practice are the area that needs further study. In this study, eleven capabilities of BIM were identified through the literature reviews and verified through preliminary interview. Quantitative questionnaire survey was conducted to examine the relationship between BIM capabilities and project performances. Lastly, fifteen interviews were conducted to verify the survey findings and a relationship framework has developed.

The results of the survey provided the following findings. Among the BIM capabilities, nine out of eleven BIM capabilities were found significantly correlated to the time perfor- mance which is $\mathrm{C}_{1}, \mathrm{C}_{2}, \mathrm{C}_{3}, \mathrm{C}_{4}, \mathrm{C}_{7}, \mathrm{C} 8, \mathrm{C} 9, \mathrm{C} 10$ and $\mathrm{C}_{11}$. Eight out of eleven BIM capabilities were found significantly correlated to the cost performance which is $\mathrm{C}_{2}, \mathrm{C}_{3}, \mathrm{C}_{4}, \mathrm{C}_{5}, \mathrm{C} 6$, $\mathrm{C}_{7}, \mathrm{C} 9$ and $\mathrm{C}_{10}$. Logistic results revealed that $\mathrm{C} 8$ and $\mathrm{C}_{9}$ are the significant predictors for project time performance; $\mathrm{C} 10$ and $\mathrm{C} 4$ are the significant predictors of the project cost performance. The results revealed that time and cost performances were influenced by BIM capabilities in quantity surveying practice. Therefore, it is important for QSs to focus these capabilities for project performance improvement. Lastly, 15 interviews were carried out to validate the quantitative results. All of the interviewees affirmed the survey results by stating that the BIM capabilities in quantity surveying practice can enhance project performance in term of time and cost aspects. A relationship framework was presented to demonstrate the identified relationships for QSs in order to increase their understanding and facilitate adoption in their practice.

The adoption of BIM in quantity surveying practice to improve project performance is emphasized in this study. This study helps to increase the awareness of BIM capabilities in the quantity surveying profession. Understanding of how the BIM application will enhance QSs' performance is important as this encourages them to benefit from the use of BIM and move away from traditional inefficient working methods. Therefore, it is recommended that the QSs should devote more effort towards BIM application to improve their job performance. Moreover, by showing the relationship between BIM capabilities and project performance, it is showed that the project performance can be enhanced by the application of BIM in quantity surveying practice. This in turn will encourage the QSs to adopt BIM in their practice and avoid lagging behind compare to other professions. It is noticeable that industry and clients requirements are changing which demand different services from the QSs. It is critical for QSs to adopt BIM for performance enhancement. Performance improvement via BIM implementation in quantity surveying practice is essential for long-term survival of quantity surveying organizations in the construction industry.

\section{ACKNOWLEDGMENTS}

The authors extend appreciation to the Institute of Research Management and Monitoring at the University of Malaya for funding the work through Project No. PGo16-2013A.

\section{REFERENCES}

(1) Chan, D. W. M., Kumaraswamy, M. M. (1997). A comparative study of causes of time overruns in Hong Kong construction projects. International Journal of Project Management, 15(1): 55-63, doi: http://dx.doi.org/10.1016/So2637863(96)00039-7.

(2) Sun, M., Meng, X. (2009). Taxonomy for change causes and effects in construction projects. International Journal of Project Management, 27(6): 560-572, doi: http://dx.doi.org/10.1016/j.ijproman.2008.10.005.

(3) Meng, X. (2012). The effect of relationship management on project performance in construction. International Journal of Project Management, 30(2): 188-198, doi: http://dx.doi.org/10.1016/j.ijproman.2011.04.002.

(4) Olatunji, O. A., Sher, W., Gu, N. (2010). Building Information Modeling and Quantity Surveying Practice. Emirates Journal for Engineering Research, 15(1): 67-70.

(5) Al-Reshaid, K., Kartam, N., Tewari, N., Al-Bader, H. (2005). A project control process in pre-construction phases: Focus on effective methodology. Engineering, Construction and Architectural Management, 12(4): 351-372, doi: http:// dx.doi.org/10.1108/09699980510608811.

(6) Gibson, J., Hamilton, M. (1994). Analysis of pre-project planning effort and success variables for capital facility projects. Austin, TX: Construction Industry Institute.

(7) Mitchell, D. (2012). 5D BIM: Creating Cost Certainty and Better Buildings. In 2012 RICS Cobra Conference, Las Vegas, Nevada USA. 
(8) Hannon, J. J. (2007). Estimators' functional role change with BIM. AACE International Transactions, 1-8.

(9) Nagalingam, G., Jayasena, H. S., Ranadewa, K. (2013, 14-15 June). Building Information Modelling and Future Quantity Surveyor's Practice in Sri Lankan Construction Industry. In Second World Construction Symposium 2013: SocioEconomic Sustainability in Construction (pp. 81-92). Colombo, Sri Lanka.

(10) Ho, T. (2012). Divisional News \& Activities. Quantity Surveying Division: Chairman's Message. http://www.hkis.org. hk/en/st/ST2012/201203/2012sto3_5f_qsd.pdf.

(11) RICS. (2012). Building Information Modeling Survey Report. Royal Institution of Chartered Surveyors. http://www. scan2bim.info/files/rics_2011_BIM_Survey_Report.pdf.

(12) Pittard, S. (2011). BIM concept and impact. http://www.isurv.com/site/scripts/documents_info.aspx?documentID=61 $83 \&$ categoryID $=390$.

(13) Smith, P. (2014). BIM \& the 5D project cost manager. Procedia-Social and Behavioral Sciences, 119: 475-484, doi: http://dx.doi.org/10.1016/j.sbspro.2014.03.053.

(14) Thurairajah, N., Goucher, D. (2012, 26-29 June). Usability and impact of BIM on early estimation practices: a cost consultant's perspective. In International Congress on Construction Management Research (pp. 555-570). Montreal, Canada.

(15) Matipa, W. M., Cunningham, P., Naik, B. (2010, 6-8 September). Assessing the impact of new rules of cost planning on building information model (BIM) schema pertinent to quantity surveying practice. In Procs 26th Annual ARCOM Conference (pp. 625-632). Leeds, UK.

(16) Stanley, R., Thurnell, D. (2014). The benefits of, and barriers to, implementation of 5D BIM for quantity surveying in New Zealand. Australasian Journal of Construction Economics and Building, 14(1):105-117, doi: http://dx.doi.org/10.5130/ ajceb.v14i1.3786.

(17) Cheung, F. K. T., Rihan, J., Tah, J., Duce, D., Kurul, E. (2012). Early stage multi-level cost estimation for schematic BIM models. Automation in Construction, 27: 67-77, doi: http://dx.doi.org/10.1016/j.autcon.2012.05.008.

(18) Monteiro, A., and Poças Martins, J. (2013). A survey on modeling guidelines for quantity takeoff-oriented BIM-based design. Automation in Construction, 35: 238-253, doi: http://dx.doi.org/10.1016/j.autcon.2013.05.005.

(19) Elbeltagi, E., Hosny, O., Dawood, M., Elhakeem, A. (2014). BIM-based cost estimation/ monitoring for building construction. International Journal of Engineering Research and Applications, 4(7): 56-66.

(20) Lee, S. K., Kim, K. R., Yu, J. H. (2014). BIM and ontology-based approach for building cost estimation. Automation in Construction, 41: 96-105, doi: http://dx.doi.org/10.1016/j.autcon.2013.10.020.

(21) Staub-French, S., Fisher, M., Kunz, J., and Paulson, A. (2003). A generic feature-driven activity-based cost estimation process. Advance Engineering Informatics, 17(1): 23-39, doi: http://dx.doi.org/10.1016/S1474-0346(03)ooo17-X.

(22) Ma, Z. L., Wei, Z. H., Song, W., Lou, Z. (2011). Application and extension of the IFC standard in construction cost estimating for tendering in China. Automation in Construction, 20(2):196-204, doi: http://dx.doi.org/10.1016/j.autcon.2010.09.017.

(23) Nour, M., Hosny, O., Elhakeem, A. (2012). A BIM based energy and lifecycle cost analysis/optimization approach. International Journal of Engineering Research and Applications, 2(6): 411-418.

(24) Wang, X. Y., Yung, P., Luo, H.B., Truijens, M. (2014). An innovative method for project control in LNG project through 5D CAD: A case study. Automation in Construction, 45: 126-135, doi: http://dx.doi.org/10.1016/j.autcon.2014.05.011.

(25) Bryman, A., Bell, E. (2007). Business research methods (2nd ed.): Oxford University Press.

(26) Creswell, J. W. (2009). Research design: Qualitative, quantitative, and mixed methods approaches (3rd ed.): SAGE Publications, Incorporated.

(27) Toor, S., Ogunlana, S. O. (2010). Beyond the 'iron triangle': Stakeholder perception of key performance indicators (KPIs) for large-scale public sector development projects. International Journal of Project Management, 28(3): 228-236, doi: http://dx.doi.org/10.1016/j.ijproman.2009.05.005.

(28) Creswell, J. W. (2005). Educational research: Planning, conducting, and evaluating quantitative and qualitative research (second ed.). New Jersey: Pearson Merrill Prentice Hall.

(29) Field, A. (2009). Discovering statistics using SPSS. Sage publications.

(30) Gee, C. 2010. The influence of building information modeling on the quantity surveying profession. (Unpublished academic exercise). South Africa: Built Environment and Information Technology.

(31) Burns \& McDonnell. (2008). Seeing the future: BIM. Benchmark, 3: 7-8.

(32) Ghanem, A. A., Wilson, N. (2011, 6-9 April). Building information modelling applied on a major csu capital project: A success story. In 47th ASC Annual International Conference (pp. 2007-2012). University of Nebraska-Lincoln, Omaha, NE.

(33) Jiang, X. (2011). Developments in cost estimating and scheduling in BIM technology (Unpublished Master's thesis). Boston, MA: Northeastern University.

(34) Shen, Z., Issa, R. R. A. (2010). Quantitative evaluation of the BIM-assisted construction detailed cost estimates. Journal of Information Technology in Construction, 15: 234-257.

(35) Hsu, R. L. (2004). Potential efficiency gains in the construction industry from the proper use of information technology (Unpublished master's thesis). Cambridge, MA: Massachusetts Institute of Technology.

(36) Aibinu, A. A., Venkatesh, S. (2012, 26-29 June). The rocky road to BIM adoption: quantity surveyors perspectives. In CIB Joint International Conference on Management of construction: research to practice (pp. 539-554). Montreal, Canada. 